\title{
Working conditions and anxiety levels of employees who have to work during the COVID-19 pandemic
}

\author{
Ülfiye Çelikkalp ${ }^{\mathrm{a}, *}$, Aylin Yalıçın Irmak ${ }^{\mathrm{b}}$ and Galip Ekuklu ${ }^{\mathrm{a}}$ \\ ${ }^{a}$ Department of Public Health, Trakya University School of Medicine, Edirne, Turkey \\ ${ }^{\mathrm{b}}$ Nursing Department, School of Health, Tekirdag Namik Kemal University, Tekirdag, Turkey
}

Received 24 April 2021

Accepted 6 August 2021

\begin{abstract}
.
BACKGROUND: This study aims to evaluate the anxiety levels of employees by determining the working conditions and protective practices in the workplace of individuals who had to work during the COVID-19 pandemic.

METHODS: The cross-sectional study was carried out with 801 employees from different sectors who continued to work during the COVID-19 pandemic.

RESULTS: The mean age of the employees was $33.1 \pm 10.3$ years, and $63.4 \%$ were male while $46.1 \%$ were workers. The GAD-7 anxiety level mean score of the participants was determined as $6.6 \pm 5.1$. Per this, $25.2 \%$ of the participants showed a high tendency to anxiety and $38.5 \%$ showed a moderate tendency. A statistically significant difference was found between anxiety level and gender, sector and profession. Besides, there was a statistically significant difference between the perception of workplace risk, the way of transportation to the workplace, the social distance in the workplace, measures taken for COVID-19 in the workplace, and anxiety levels $(p<0.05)$. In the multiple regression analysis, age, gender, work sector, COVID-19 anxiety levels, infection status, knowledge level and life satisfaction levels were determined as effective predictors on common anxiety disorder and explained $23.2 \%$ of the developed model variance $(\mathrm{R} 2=0.232, p \leq 0.001)$.

CONCLUSION: During the pandemic, it was determined that the anxiety susceptibility levels of the employees were very high and their protective practices against COVID-19 in the workplace were insufficient.
\end{abstract}

Keywords: Employees, outbreak, Turkey, COVID-19

\section{Introduction}

The coronavirus outbreak occurred as a pneumonia outbreak in Wuhan, Hubei Province, China in December 2019 and was later named COVID-19 by the World Health Organization [1]. The COVID-19 pandemic has caused people around the world to face physiological and psychological stress [2]. It is reported that life-threatening pandemics increase individuals' anxiety levels, which in turn increases their avoidance behaviors and brings social life to a

*Address for correspondence: Ülfiye Çelikkalp, Department of Public Health, Trakya University School of Medicine, 22030, Edirne, Turkey. E-mail: ulfiyem@yahoo.com. halt [3]. Especially in the COVID-19 pandemic process, it is emphasized in the studies that it may cause anxiety and fear in the society due to reasons such as being a new infection, having limited information about it $[4,5]$, not having an effective treatment or vaccine, and having a high fatality rate and being contagious [6-8]. Also, individuals under isolation and quarantine measures may experience anxiety/anxiety disorders, depression, post-traumatic stress disorder, insomnia, frustration, anger, and nervousness [9-11]. In the literature, various authors define anxiety as the disturbing feeling of insecurity [12], as a normal, adaptive, and widespread emotional response to a variety of threatening or dangerous situations or con- 
ditions. In this context, anxiety, in general, can be regarded as "to be stimulated", "unpleasant feeling" and "feature" in response to situations that are considered "dangerous" or "threatening". Anxiety includes state and trait anxiety. However, excessive anxiety indicates an unhealthy state [13]. According to epidemiological research findings, anxiety disorders are the most common types of psychiatric diseases in the world [14]. The anxiety prevalence worldwide is around $7.3 \%$ and the common anxiety disorder prevalence is around $2.2 \%$ [15]. In the studies conducted, the prevalence of anxiety was found to be related to factors such as physical health, lifestyle, and habits (sleep time, exercise, smoking), and workrelated conditions (shift work, working time, conflict, and exposure to violence) $[16,17]$. Besides, it was reported that while there was a negative relationship between anxiety and performance, success, cognitive performance, motivation, and self-regulation, anxiety had a positive relationship with creative thinking and constructive-creative behavior [18]. In addition, the events related to the social and working life experienced by individuals also affected their life satisfaction negatively. In the literature, some studies show that the undesirable experiences in the job interact negatively with the work and life satisfaction of the personnel performing these tasks $[18,19]$.

According to the May 2020 Screening Data of Mental Health America, more than 211.000 people participated in online mental health screening. Accordingly, possible anxiety or depression and suicidal intention were identified in 88.000 participants. When the data from the pre-COVID-19 pandemic in January were compared with the data from the postCOVID-19 pandemic in May, anxiety had increased by $370 \%$ and depression had increased by $394 \%$. Depression or anxiety was detected in 8 or 9 people out of 10 under the age of 25 [20]. The data evokes the question of whether a new psychiatric outbreak is approaching.

In the literature, it is emphasized that health problems such as anxiety and depression will increase in the coming years [21]. Research on stress and anxiety reveal that physiological and psychological destruction occurs especially in busy working groups, which negatively affects the health and organizational success of individuals $[2,22]$. In this context, the health problems of the employees who work during the pandemic process need to be determined. Since these problems directly affect public health, they should be specially addressed. This study aims to evaluate the anxiety levels and life satisfaction of employees by determining the working conditions and protective practices in the workplace of individuals who had to work during the COVID-19 pandemic process.

\section{Materials and methods}

\subsection{Design and participants}

This cross-sectional study included individuals between the ages of 18-65 who could read and write in Turkish, continued to work in the COVID-19 pandemic process, could be reached on social media, and agreed to participate in the study. To collect data without choosing samples, 815 people who were available on social media between 25 May and 01 June 2020 and volunteered to participate in the study were contacted. The study was carried out with 801 people since 14 of the participants who responded did not meet the inclusion criteria.

\subsection{Instruments}

In the collection of the data, a personal information form was created as a result of examining the literature, Generalized Anxiety Disorder Scale (GAD-7), and Satisfaction with Life Scale was used.

\subsubsection{The personal information form}

The personal information form included questions such as socio-demographic characteristics (age, marital status, gender, educational status, number of children, occupation, years of work, place of residence, monthly income), weekly working hours, shift working status, service bus use status, infection with COVID-19 status, anxiety about getting COVID19 , knowledge status about COVID-19, contact with COVID-19 at work, and the use of personal protection at work. In some of these questions, employees were asked to evaluate themselves. The participant evaluated the question related to COVID-19 anxiety status by giving a score between 0 (lowest) and 10 (highest). In the question about their knowledge level on COVID-19, the person evaluated himself/herself as sufficient or inadequate in line with the information he/she received from the workplace or various data sources.

\subsubsection{The Generalized Anxiety Disorder (GAD-7) Scale}

The Generalized Anxiety Disorder (GAD-7) Scale Test was first developed in 2001 by Kessler et al. 
and was adapted to Turkish and its validity and reliability were proven by Konkan et al. [23]. GAD-7 is a short self-report test developed by Spitzer et al. based on DSM-IV-TR criteria and to evaluate the generalized anxiety disorder. It is a 4-point Likert-type scale $(0=$ none, $1=$ many days, $2=$ more than half the days, $3=$ almost every day) with 7 factors that evaluate the lives of the participants in the last 2 weeks. The total scores obtained from the scale, 5, 10, and 15 , are cut-off points for mild, moderate, and severe anxiety, respectively. Individuals who receive a total score of 10 or above must have their GAD-7 diagnosis investigated and confirmed by other methods. When the total score threshold was selected as 10 , its sensitivity was detected as $89 \%$ and its specificity was detected as $82 \%$ for the diagnosis of GAD-7 [23]. The Cronbach's alpha value was found as 0.89 in the present study.

\subsubsection{Satisfaction with Life Scale}

The Satisfaction With Life Scale (SWLS) was developed by Diener, Emmons, Larsen, and Griffin (1985), its Turkish validity and reliability study was carried out by Dağli and Baysal (2016) and consists of 5 items under a single factor structure. It is a 5-point Likert-type scale, with the responses; "Completely disagree (1), Somewhat agree (2), Agree moderately (3), Strongly agree (4) and Completely agree (5)". As the score obtained from the scale increases, the life satisfaction of the individual increases [24]. In this study, the Cronbach's alpha value of the scale was found to be 0.87 .

\subsection{Data collection}

As measures such as social distance, isolation, and quarantine continue in our country due to the COVID19 pandemic, it was deemed appropriate to conduct the study online via digital tools. The questionnaire was administered between the 74th and 80th days of the pandemic process. In this context, the online questionnaire created in Google Forms was announced on social networks and asked to be answered by the participants. Since the data were collected through Google Forms, the research was mainly based on the volunteers' participation.

\subsection{Ethical considerations}

Before the start of the study, a study permit was obtained from the Ministry of Health, and ethics committee approval was obtained from the Ethics
Committee of Trakya University Faculty of Medicine Non-Interventional Clinical Researches (Date 22.05. 2020, TÜTF-BAEK/205). Also, the purpose and duration of the study were explained in the questionnaire form, and online consent was obtained from those who agreed to participate in the study.

\subsection{Data analysis}

The data were analyzed in SPSS 21.00 package program. Descriptive statistics (number, mean, median, standard deviation) were used to analyze the data. Independent sample $t$-test, one-way variance analysis, and Pearson correlation analysis were used to compare numerical variables between groups. Multiple regression analysis was carried out by associating the Generalized Anxiety Disorder total score, which is the dependent variable, with a number of the independent variables (age, gender, profession, sector, the status of being infected with COVID19; COVID-19 anxiety level, knowledge status). The results were evaluated in a confidence interval of $95 \%$ and with the level of significance at $p<0.05$.

\section{Results}

The mean age of the participants who had to work during the COVID-19 pandemic period was $33.1 \pm 10.3$ years, while $63.4 \%$ of the participants were male and $50.6 \%$ were married. It was determined in the study that $46.1 \%$ of the participants were workers, $31.6 \%$ of them worked in the health sector and the average working year was $8.9 \pm 10.3$. The weekly working hours of the participants were determined as $42.5 \pm 15.2$ (hours/week). It was also understood that $62.5 \%$ of these employees worked overtime during the pandemic period. It was determined that $35.2 \%$ of the employees worked in shifts, $70.0 \%$ worked with the flexible working model during the pandemic period, and $43.7 \%$ went to work with their vehicle. The two most common fears that employees experienced most during the COVID-19 pandemic were losing loved ones (35.7\%) and failure to meet basic needs (29.0\%) (Table 3). Moreover, the anxiety score of the employees related to being infected by COVID-19 was determined as $6.2 \pm 2.76$.

GAD-7 was used to assess the anxiety levels of employees during the COVID-19 outbreak. In this assessment, the cut-off points were used and according to this, during COVID-19 outbreak, the rate of those with no or mild anxiety tendencies was $38.5 \%$. On the other hand, $36.2 \%$ of the employees showed 
Table 1

Anxiety levels of employees

\begin{tabular}{|c|c|c|c|c|c|c|}
\hline \multirow[t]{2}{*}{ Generalized Anxiety Disorder (GAD-7) } & \multicolumn{2}{|c|}{ None-light } & \multicolumn{2}{|c|}{ Middle } & \multicolumn{2}{|c|}{ Serious } \\
\hline & $n$ & $\%$ & $n$ & $\%$ & $n$ & $\%$ \\
\hline & 309 & 38.5 & 290 & 36.2 & 202 & 25.2 \\
\hline & & Mean & & \multicolumn{3}{|c|}{ Standard deviation } \\
\hline Generalized Anxiety Disorder (GAD-7) scores & & 6.6 & & \multicolumn{3}{|c|}{5.1} \\
\hline
\end{tabular}

moderate anxiety and $25.2 \%$ had a high level of anxiety. The GAD-7 anxiety level mean score of the participants was determined as $6.6 \pm 5.1$ (Table 1).

In the study group, anxiety scores were found higher in female and single people than male and married people. However, workers under the age of 34 were found to have higher levels of anxiety $(p<0.05)$ (Table 2). Those who continued to work during the COVID-19 pandemic, those who caught COVID-19, had close contact and those who did not know their infection status had a higher GAD-7 score $(p<0.05)$ (Table 2).

A statistically significant difference was found between the anxiety levels of the employees and their working characteristics such as the sector, profession, workplace risk perception, way of transportation to the workplace, social distance in the workplace, measures taken for COVID-19 at the workplace $(p<0.05)$. When the source of the difference was investigated, employees with higher levels of anxiety were the ones who were private sector workers, worked in the education sector, went to work by public transport, worked in high-risk workplaces, had personal protective equipment shortages, worked in workplaces where the social distance rules were not applied, and therefore indicated that inadequate measures were taken in the workplace. When the profession group was examined, the anxiety scores of the private sector workers were the highest, the anxiety scores of the tradesmen are the lowest, and the difference arose from the tradesmen. On the other hand, those who worked in the food sector had lower scores and those who worked in the education and health sector had higher anxiety scores (Table 2). No significant relation was found between doing overtime and shift work status of the employees and the GAD-7 score $(p>0.05)$.

In the study, the anxiety scores of the participants who were evaluated to have an insufficient level of knowledge about COVID-19 were higher than those who had sufficient knowledge on the subject and the differences between them were statistically significant $(p<0.05)$ (Table 2).
While there was a positive weak correlation $(\mathrm{r}=-0.35, p<0.000)$ between employees' anxiety of contracting COVID-19 while working and GAD-7 scores, there was a negative and significant correlation between life satisfaction $(\mathrm{r}=-0.23, p<0.000)$ and age $(\mathrm{r}=-0.14, p<0.000)$ (Table 3$)$.

Multiple regression analysis was carried out by associating independent variables with GAD-7 total scores in the study (Table 4). The model explaining the anxiety levels ( $\mathrm{R} 2=0.232, p \leq 0.001)$ of individuals who had to work during the COVID-19 pandemic period was found to be significant. In the model; age $(\beta=-0.082, p \leq 0.05)$, gender $(\beta=-0.073, p \leq 0.05)$, the sector of employment $(\beta=-0.104, p \leq 0.05)$, COVID-19 anxiety level $(\beta=0.302, p \leq 0.001)$ having COVID-19 disease $(\beta=0.068 p>0.05)$, COVID-19 knowledge level $(\beta=0.135, p \leq 0.001)$ and life satisfaction level $(\beta=-0.184, p \leq 0.001)$ were identified as effective predictors and the model explained $23.2 \%$ of the variance (Table 4 ).

\section{Discussion}

This study was planned to investigate the working conditions and anxiety levels of individuals working in sectors that continued to work during the COVID-19 outbreak in Turkey. Of course, workers with different workplaces are exposed to different health and safety hazards. However, due to the covid19 pandemic, which emerged suddenly and caused many people to become ill and die, similar psychological effects were observed, especially in working individuals $[10,25]$. In this study, it was found that the level of anxiety susceptibility of the employees during the pandemic was very high. $25 \%$ of the employees scored above the GAD-7 cut-off score, meaning that there was a possibility of anxiety disorder to occur in one in every 4 employees. According to the literature, the prevalence of lifetime anxiety is between $2.2 \%$ and $5 \%$ [15, 25]. Our study result is very high compared to the level of anxiety in the general population before the COVID-19 pandemic process, but it is consistent with the findings of the 
Table 2

Comparison of GAD-7 scale mean scores according to the socio-demographic and study characteristics of the participants $(n=801)$

\begin{tabular}{|c|c|c|c|}
\hline \multirow[t]{2}{*}{ Descriptive variables (n) } & \multicolumn{2}{|c|}{$\begin{array}{c}\text { Generalized } \\
\text { Anxiety } \\
\text { Disorder } \\
\text { (GAD-7) } \\
\text { scores }\end{array}$} & \multirow[t]{2}{*}{$p$} \\
\hline & Mean & SD & \\
\hline \multicolumn{4}{|l|}{ Gender } \\
\hline Female (293) & 7.5 & 5.2 & \multirow[t]{2}{*}{0.000} \\
\hline Male (508) & 6.1 & 5.0 & \\
\hline \multicolumn{4}{|l|}{ Age } \\
\hline$\leq 34$ age & 7.1 & 5.9 & \multirow[t]{2}{*}{0.000} \\
\hline$\geq 35$ age & 5.6 & 4.6 & \\
\hline \multicolumn{4}{|l|}{ Marital status } \\
\hline Married (405) & 6.2 & 5.1 & \multirow[t]{2}{*}{0.017} \\
\hline Single (396) & 7.0 & 5.2 & \\
\hline \multicolumn{4}{|l|}{ Employment } \\
\hline Private sector worker (309) & 7.1 & 4.9 & \multirow[t]{4}{*}{0.040} \\
\hline State worker (369) & 6.4 & 5.2 & \\
\hline Tradesmen (66) & 5.3 & 5.1 & \\
\hline Daily wage worker / informal (67) & 6.6 & 5.1 & \\
\hline \multicolumn{4}{|l|}{ Sector } \\
\hline Health (253) & 7.4 & 4.9 & \multirow[t]{6}{*}{0.000} \\
\hline Education (61) & 9.0 & 6.0 & \\
\hline Security (38) & 4.8 & 5.2 & \\
\hline Industry (111) & 5.4 & 4.1 & \\
\hline Service $(235)$ & 7.0 & 5.1 & \\
\hline Food (46) & 5.3 & 4.7 & \\
\hline \multicolumn{4}{|l|}{ Overtime } \\
\hline Yes $(501)$ & 6.9 & 5.1 & \multirow[t]{2}{*}{0.107} \\
\hline No $(300)$ & 6.3 & 5.1 & \\
\hline \multicolumn{4}{|l|}{ Shift work } \\
\hline Yes (382) & 6.5 & 5.0 & \multirow[t]{2}{*}{0.437} \\
\hline No (519) & 6.8 & 5.2 & \\
\hline \multicolumn{4}{|l|}{ COVID-19 knowledge level } \\
\hline Sufficient (632) & 6.2 & 4.9 & \multirow[t]{2}{*}{0.000} \\
\hline Insufficient (169) & 8.3 & 5.5 & \\
\hline \multicolumn{4}{|l|}{ COVID-19 infected condition } \\
\hline COVID-19 PCR positive (10) & 8.5 & 5.1 & 0.001 \\
\hline $\begin{array}{l}\text { Close contact with COVID-19 } \\
\text { positive (17) }\end{array}$ & 8.4 & 5.4 & \\
\hline I don't know (118) & 8.2 & 4.9 & \\
\hline No $(656)$ & 6.3 & 5.1 & \\
\hline Measure for covid at work & & & \\
\hline Sufficient (500) & 5.9 & 5.0 & 0.000 \\
\hline Insufficient (301) & 7.6 & 5.2 & \\
\hline PPE shortage in the workplace & & & \\
\hline Yes (197) & 7.7 & 5.4 & 0.000 \\
\hline No (604) & 6.3 & 4.9 & \\
\hline Social distance at work & & & \\
\hline Applying (550) & 6.4 & 4.9 & 0.025 \\
\hline Not applicable (251) & 7.2 & 5.4 & \\
\hline Transportation to the workplace & & & \\
\hline Self tool (350) & 6.0 & 4.9 & 0.000 \\
\hline Public transport (208) & 7.3 & 4.9 & \\
\hline Service (243) & 7.8 & 5.2 & \\
\hline Workplace risk perception & & & \\
\hline Low $(150)$ & 4.9 & 4.8 & 0.000 \\
\hline Intermediate (321) & 6.2 & 4.7 & \\
\hline High (330) & 7.8 & 5.3 & \\
\hline
\end{tabular}

Table 3

Generalized Anxiety Disorder (GAD-7) scores of the participants and their relationship with some variables

\begin{tabular}{lccccr}
\hline Variables & & 1 & 2 & 3 & 4 \\
\hline (1) Generalized Anxiety & $\mathrm{r}^{*}$ & 1 & & & \\
$\quad$ Disorder (GAD-7) scores & $p$ & & & & \\
(2) Satisfaction With Life & $\mathrm{r}^{*}$ & -0.234 & 1 & & \\
Scale (SWLS) & $p$ & 0.000 & & & \\
(3) Concern about having & $\mathrm{r}^{*}$ & 0.351 & -0.086 & 1 & \\
COVID-19 & $p$ & 0.000 & 0.015 & & \\
(4) Age & $\mathrm{r}^{*}$ & -0.137 & 0.107 & -0.003 & 1 \\
& $p$ & 0.000 & 0.002 & 0.943 & \\
\hline
\end{tabular}

*(Pearson correlation coefficient).

study conducted during the pandemic process. In the literature, similar to the findings of this research, there are studies that show that anxiety prevalence is higher in extraordinary times $[25,26]$. In an online community-based study by Mental Health America, participants' anxiety thoughts were found to be quite high and the results were interpreted to be at a worrying level [20]. Çitak and Pekdemir reported that anxiety levels of individuals who worked during the COVID-19 pandemic were higher than those who did not work [26]. In the literature, it is suggested that life-threatening pandemics increase anxiety levels of individuals due to the lack of effective treatment methods $[2,6,27]$. This is because anxiety is a vague and unpleasant feeling of fear that can emerge. Anxiety levels increase due to the discomfort or stress experienced by the person when he/she feels himself/herself to be in danger [28].

In this study, a significant difference was found between generalized anxiety tendency levels of male and female employees. Although studies report that anxiety disorders are more common in women, there are hypotheses that state this increased vulnerability in women is due to physiological reactivity and hormones $[29,30]$. The results obtained from the study are compliant with the literature.

There are studies showing that there is a significant difference between the findings of stress, anxiety and depression according to age in studies conducted with employees during the Covid-19 pandemic. In some studies, it is reported that young workers are more sensitive psychologically due to their age and lack of professional experience, and therefore they have higher stress and anxiety scores [31, 32]. In different studies, it is seen that there are studies indicating that the level of stress increases as age increases, and it is known that this result may be related to the effect of the Covid-19 virus causing more severe consequences with increasing age [33]. Increasing 
Table 4

Regression model of variables effective on anxiety levels of employees

\begin{tabular}{|c|c|c|c|c|c|c|}
\hline Model & Variables & $\mathrm{B}$ & SE & Standard $\beta$ & $\mathrm{F}$ & Adjusted $\mathrm{R}^{2}$ \\
\hline $\begin{array}{l}\text { Anxiety levels of employees during the } \\
\text { COVID-19 pandemic }\end{array}$ & $\begin{array}{l}\text { Constant } \\
\text { Age } \\
\text { Gender } \\
\text { Employment } \\
\text { Sector } \\
\text { COVID-19 concern } \\
\text { Workplace risk } \\
\text { COVID-19 infected } \\
\text { COVID-19 knowledge level } \\
\text { Satisfaction With Life Scale }\end{array}$ & $\begin{array}{c}7.045 \\
-0.041 \\
-0.773 \\
-0.061 \\
-0.302 \\
0.579 \\
0.417 \\
0.320 \\
0.898 \\
-0.216\end{array}$ & $\begin{array}{l}1.215 \\
0.016 \\
0.364 \\
0.205 \\
0.106 \\
0.062 \\
0.233 \\
0.150 \\
0.214 \\
0.038\end{array}$ & $\begin{array}{c}-0.082^{*} \\
-0.073^{*} \\
0.110 \\
-0.104^{*} \\
0.302^{* *} \\
0.061 \\
0.068^{*} \\
0.135^{* *} \\
-0.184^{* *}\end{array}$ & $26,552^{* *}$ & 0.232 \\
\hline
\end{tabular}

Note. ${ }^{*} p \leq 0.05,{ }^{* *} p \leq 0.001$.

age and professional knowledge and experience is an expected finding to reduce anxiety, and our results are consistent with the literature.

In this study, the anxiety levels of the participants varied according to the profession and the sector they worked in. One of the important results here is that the level of anxiety of employees working in the private sector was higher than that of state workers. A lower level of anxiety in the state workers servant group is an expected result. Possible reasons for this may be the fact that state workers are publicly supported, that is, they have the continuation of the job guarantee, no issues such as loss of income, and better implementation of flexible working hours in the pandemic process compared to the private sector workers and tradesmen. Because during this period, it is likely that many workplaces have reached a point of closing down, and thus, due to unemployment and economic reasons, the level of anxiety will increase. It is reported in the literature that the level of anxiety of unemployed individuals is higher than others [26].

However, when we examine it as a professional group, we see that the education sector employees have the highest anxiety score. This may be related to the higher education levels of the education sector employees compared to other sectors (workers, tradesmen, security...) and their consequently higher awareness on the subject. In the study conducted by Kayapinar et al. with teachers during the pandemic process, it was reported that teachers' levels of anxiety and depression were high and their musculoskeletal discomfort increased as a result of this situation [34]. The psychosocial repercussions of the COVID-19 epidemic have not been fully evaluated yet, and different occupational studies are required in this area.

The anxiety levels of health workers are expected to be high due to factors such as working at the front lines, high risk of infection, increased and intense workload [35]. The reason for this difference can be explained by the fact that healthcare professionals have a better understanding of the steps of protection with their professional knowledge and experience, and that their psychological resistance is higher. Our findings are consistent with the studies conducted [6]. In a study conducted by $\mathrm{Li}$ et al. in China on groups of people who are nurses and those who are not, it was found that although the nurses had a high level of anxiety, there were no differences in anxiety levels between nurses and the general population during the COVID-19 pandemic process. This result can be attributed to the implementation of a very strict isolation policy towards the public in China and the lack of psychological resilience in society [6].

Working conditions affect psychosocial health. Shift work, overwork, and work intensity increase work stress $[17,36]$. However, in this study, it was determined that features such as shift work and overwork did not affect anxiety levels. This is because there is an increasing state of anxiety towards the uncertainty of the pandemic process in the whole society [25]. In this case, it is not the work hours that increase the anxiety level of the employees, but the existence of obstacles in the self-protection of the individual in the work environment. Because in this study, at the workplace, the level of anxiety increases in situations where there is a problem in accessing personal protective equipment when social distance rule is not applied, adequate measures are not taken for COVID-19, and service bus is taken to go to the workplace. International and national organizations, even in many studies, report that the use of masks, at least 1.5-2 meters of social distance, and hand hygiene should be applied in the workplace to prevent COVID-19 infection [1, 25, 37]. In the fight against the COVID-19 pandemic in Japan, it is stated 
that measures to reduce physical contacts such as restrictions on crowded groups, social distance application, mask use, and handshake are very important in success [37]. In different studies, studies report that employees have difficulties in accessing personal protective equipment $[38,39]$. Besides, the anxiety levels of the employees may have been affected by the average number of employees in the same environment and problems in accessing personal protective equipment. The insufficiency of such vital preventive measures is an undesirable situation, and it will seriously affect the health of the employees. In this case, it is recommended that those who work in risky working environments in both national and international legislation should exercise their right to refrain from working until necessary measures are taken [40]. However, it is a known fact that especially those working in the private sector cannot exercise their rights adequately due to unemployment anxiety.

COVID-19 is the first new occupational disease described in this decade [41]. In many countries (Italy, Germany, Belgium, South Africa, Canada, Malaysia, the United States of America), employees who have a high risk of infection are reported to be eligible for compensation as a work-related accident/occupational disease [42]. The Ministry of Health in Turkey still has not announced how many employees there are who are diagnosed with COVID19. There is even an explanation stating that it will not be accepted as a work accident/occupational disease. While some institutions/workplaces throughout the country make a work accident/occupational disease notification, some institutions are known not to have made these notifications. The Ministry's lack of clarity on this issue increases this uncertainty. In the literature, it is reported that transparently disclosing information on the pandemic will have a positive effect on the social and psychological situation as well as being very beneficial for the subsequent psychological interventions [6].

According to the results of the regression and correlation analysis, there is a positive and significant correlation between concern about getting infected with COVID-19 and anxiety. Like the thought of getting infected increases, anxiety levels increase. As the level of anxiety increases, employee's satisfaction with life is negatively affected. While COVID-19 fatality rate varies by country, when these results are interpreted in general with all the findings in the study, despite quarantine and curfews applied to the majority of the society due to high fatality rate, lack of treatment methods, high contagiousness [37-39], the employees' having to work and the deficiencies in protective practices in the workplace are thought to increase anxiety levels of employees.

In the world, which has lived through an extraordinary period with the COVID-19 outbreak, serious changes in social, economic, cultural, and many other areas are experienced [3]. Due to these changes that occurred because of the COVID-19 pandemic, increased anxiety levels in society and employees may cause many problems $[11,26]$. The vast majority of the employees in this study stated that they had the fear of losing their loved ones during the pandemic process, their motivation and life satisfaction decreased and their anxiety levels increased. It is reported in the literature that anxiety has negative effects on cognitive behavior, motivation, and life satisfaction, and it may also cause other health problems $[18,22]$. Although the motivation of the employee decrease is an important reason for absenteeism, it can also be a reason for work accidents. Both public health and the national economy need to bring the work environments of the employees to a level that does not harm their health. Occupational Safety and Health Administration (OSHA) emphasizes that in addition to the general measures against the COVID-19 outbreak in workplaces, it is important to support employees in psychosocial aspects, thus make them feel safe and reduce the anxiety that they may have developed [43]. In this context, psychological counseling lines have been established in many countries such as China, Italy, Spain, Germany, and France [28]. On 9 April 2020, in Turkey, the Mental Health Support System hotline was established that can be accessed by mobile applications. This is a good implementation.

\subsection{Limitations and strengths of the study}

A possible limitation of the study is that community-based assessments, which are normally done face-to-face, are online due to the outbreak. However, due to the risk of transmission during the COVID-19 pandemic process, many studies are carried out online around the world. The study will bring together employees from different sectors, and the results we have obtained regarding the psychosocial status of employees / individuals who constitute a significant part of the society will contribute to the literature as it concerns public health. Our study will contribute to reinforce the results of specific studies that will be done according to professions in the future. Since a valid and reliable standardized 
measurement tool was used in the study, the participants were not diagnosed with anxiety and the risk group was tried to be determined.

Our study is one of the first articles that examines the work environment and anxiety problems of individuals who have to work in the COVID-19 pandemic and makes recommendations for employees to be healthy. In this context, the findings are very important for employers and government administrators as they emphasize that the mental health of employees should not be ignored.

\section{Conclusion}

During the COVID-19 epidemic, people had to spend most of their time at home during the limited or strict quarantine process implemented due to the increasing cases in Turkey. While these measures apply to individuals who do not work harder, millions of workers have been forced to continue working. In the study, the anxiety tendencies of the employees were high during the COVID-19 pandemic process. Although the level of anxiety varies according to the sector the employees work in, it is higher in workplaces where inadequate measures are taken against the COVID-19. The level of anxiety has found to be higher especially in private sector workers, in workplaces where protective measures such as personal protective equipment and social distance are not taken, and in employees who do not have enough information about COVID-19. It has determined that there was no significant difference between overtime and shift work and anxiety.

In the literature, it is emphasized that health problems such as anxiety and depression will increase in the coming years [19]. Research on stress and anxiety reveal that physiological and psychological destruction occurs especially in busy working groups and negatively affects the health and organizational success of individuals $[10,20]$. Because high anxiety tendencies of employees may not only bring different health problems, but also negatively affect work performance and motivations, and cause business and economic problems. Therefore, the controlled hierarchy required for the health and safety of the employees in the workplaces should be carefully followed, the risk of infection of the employees should be reduced and the employees should feel safe. For this purpose, training of employees, informing them about new developments about the period should be constantly updated via online training systems.
However, if adequate personal protective equipment and social distance are maintained in the working environment, employees will feel safe and their anxiety levels will be reduced. Employees who are at risk should be identified and these employees should be provided with necessary social and mental health support at an early stage. It is recommended to carry out studies that examine cause-effect relationships specific to occupations in the future.

\section{Acknowledgments}

The authors would like to thank all participants for their cooperation.

\section{Conflict of interest}

The authors declare that there are no conflicts of interest.

\section{References}

[1] Dehghania F, Omidib F, Yousefinejada S, Taheri E. The hierarchy of preventive measures to protect workers against the COVID-19 pandemic: A review. Work. 2020;67:771-7.

[2] Yang Q, Huo J, Li J, Jiang Y. Research on the influence of the COVID-19 epidemic on work stress of returning workers in China: A study based on empirical analyses of industrial enterprises. Work. 2020;67:67-79.

[3] Bostan S, Erdem R, Öztürk YE, Kiliç T, Yilmaz A. The effect of COVID-19 pandemic on the Turkish society. Electronic Journal of General Medicine. 2020;17(6):2-8.

[4] Bao Y, Sun Y, Meng S, Shi J, Lu L. 2019-nCoV epidemic: address mental health care to empower society. The Lancet. 2020;395(10224):E37-8.

[5] Shigemura J, Ursano RJ, Morganstein J.C, Kurosawa M, Benedek DM. Public responses to the novel 2019 coronavirus (2019-nCoV) in Japan: Mental health consequences and target populations. Psychiatry and Clinical Neurosciences. 2020;74:277-83.

[6] Li Z, Ge J, Yang M, Feng J, Qiao M, Jiang R, et al. Vicarious traumatization in the general public, members, and nonmembers of medical teams aiding in COVID-19 control. Brain Behavior, and Immunity. 2020; 88:916-19.

[7] Jung SJ, Jun JY. Mental health and psychological intervention amid covid-19 outbreak: perspectives from South Korea. Yonsei Medical Journal. 2020; 61(4):271-2.

[8] Xiao H, Zhang Y, Kong D, Li S, Yang, N. The effects of social support on sleep quality of medical staff treating patients with coronavirus disease 2019 (COVID-19) in January and February 2020 in China. Medical Science Monitor. 2020;26:e923549-1.

[9] Brooks SK, Webster RK, Smith LE, Woodland L, Wessely S, Greenberg N, et al. The psychological impact of quarantine and how to reduce it: rapid review of the evidence. Lancet. 2020;395:912-20. 
[10] Dey A, Majumdar P, Saha A, Sahu S. COVID-19 pandemic lockdown induced altered sleep/wake circadian rhythm, health complaints and stress among traffic police personnel in India, Chronobiology International. 2021; 38(1):140-8.

[11] Majumdar P, Biswas A, Sahu S. COVID-19 Pandemic and lockdown: cause of sleep disruption, depression, somatic pain and increased screen exposure of office workers and students in India, Chronobiology International. 2020;37(8): 1191-200.

[12] Tekkurşun Demir G, Cicioğlu H. İbrahim, İlhan EL. Athlete's Anxiety to Catch the Novel Coronavirus (Covid-19) Scale (AACNCS): Validity and reliability study. Journal of Human Sciences. 2020;17(2):458-68.

[13] Kutanis ÖR, Tunç T. The relationship between self-esteem and state-trait anxiety in nurses: a sample of a university hospital. Industrial Relations and Human Resources Journal. 2013;15(2):1-15.

[14] Stein DJ, Scott KM, Jonge P, Kessler RC. Epidemiology of anxiety disorders: from surveys to nosology and back. Dialogues in Clinical Neuroscience. 2017;19:127-35.

[15] Thibaut F. Anxiety disorders: a review of current literature. Dialogues in Clinical Neuroscience. 2017;19:87-8.

[16] Ergun R, Ergun D, Ergan B. Anxiety and depression in intensive care unit staff. Turkish Journal of Medical and Surgical Intensive Care Medicine. 2017;7(3):93-8.

[17] Majumdar P, Barman A, Chakraborty P, Sahu S. COVID19 Pandemic and rotational shift work: impact on physical and mental health of Indian nurses, International Journal of Research, 2020; 6(2):60-72.

[18] Bria M, Baban A, Andreica AS, Dumitraşcu DL. Burnout and turnover intentions among Romanian ambulance personnel. Procedia-Social and Behavioral Sciences. 2013; 84:801-5.

[19] Eroğlu BS, Arikan S. Acil yardim çalişanlarinda travma, tükenmişlik ve yaşam doyumu ilişkilerinde stresle başa çikmanin moderatörlük rolü. Türk Psikoloji Dergisi. 2016; 31(78):45-57.

[20] Alexandria VA. Mental health America Releases May 2020 Screening Data; 88,000 have anxiety or depression, and results point to possible epidemic of suicidal ideation. 2020. Available from: https://www.mhanational.org/mentalhealth-america-releases-may2020-screening-data-88000have-anxiety-or-depression-and-results.

[21] Hassan S, Husain W. The different levels of depression and anxiety among Pakistani professionals. Insights Depress Anxiety. 2020;4:012-8.

[22] Koç S, Özkul AS, Özdemir Ürkmez D, Özkul Özel H, Çelik Çevik L. An analysis of level and sources of stress in nurses working in a health organization. Okmeydani Tip Dergisi. 2017;33(2):68-75.

[23] Konkan R, Şenormanci Ö, Güçlü O, Aydin E, Sungur MZ. Validity and reliability study for the Turkish adaptation of the Generalized Anxiety Disorder-7 (GAD-7) scale. Archives of Neuropsychiatry. 2013;50:53-8.

[24] Dağli A, Baysal N. Adaptation of the satisfaction with life scale into Turkish: the study of validity and reliability. Electronic Journal of Social Sciences. 2016;15(59):1250-62.

[25] Omidi L, Moradi G, Sarkari NM. Risk of COVID-19 infection in workplace settings and the use of personal protective equipment. Work. 2020;66:377-8.

[26] Çitak Ş, Pekdemir Ü. An analysis on sleep habits and generalized anxiety levels of Individuals during the COVID-19 pandemic. Journal of Family, Counseling and Education. 2020;5(1):60-73.
[27] Özcan M, Uğuz F, Cilli AS. The prevalence of generalized anxiety disorder and comorbidity among psychiatric outpatients. Turk Psikiyatri Dergisi. 2006;17(4):276-85.

[28] Li W, Yang Y, Liu Z-H, Zhao Y-J, Zhang Q, Zhang L, et al. Progression of mental health services during the COVID19 Outbreak in China. International Journal of Biological Sciences. 2020;16(10):1732-8.

[29] Fernandes MA, Ribeiro HKP, Santos JDM, Monteiro CFS, Costa RS, Soares RFS. Prevalence of anxiety disorders as a cause of workers' absence. Revista Brasileira de Enfermagem. 2018;71(5):2213-20.

[30] Bal U, Çakmak S, Uğuz Ş. Gender differences in symptoms of anxiety disorders.. Archives Medical Review Journal. 2013;22(4):441-59.

[31] Li R, Chen Y, Lv J, Liu L, Zong S, Li H, et al. Anxiety and related factors in frontline clinical nurses fighting COVID19 in Wuhan. Medicine. 2020;24;99(30):e21413.

[32] Zandiana H, Sakhab MA, Nasiria E, Moghadama TZ. Nursing work intention, stress, and professionalism in response to the COVID-19 outbreak in Iran: A cross-sectional study. Work. 2021;68:969-79.

[33] Yörük S, Güler D. The relationship between psychological resilience, burnout, stress, and sociodemographic factors with depression in nurses and midwives during the COVID19 pandemic: A cross-sectional study in Turkey. Perspect Psychiatr Care. 2021;57(1):390-8.

[34] Kayabinar E, Kayabinar B. Onal B, Zengin HY, Kose N. The musculoskeletal problems and psychosocial status of teachers giving online education during the COVID-19 pandemic and preventive telerehabilitation for musculoskeletal problems. Work. 2021;68:33-43.

[35] Afshari D, Nourollahi-darabad M, Chinisaz N. Demographic predictors of resilience among nurses during the COVID-19 pandemic. Work. 2021;68:297-303.

[36] Yaşar A, Alpsoy F, Taçgin E. Evoluation of call centers in terms of work health and security. Ankara Üniversitesi Sosyal Bilimler Dergisi. 2016;7(1):1-29.

[37] Lu N, Cheng KW, Qamar N, Huang KC, Johnson JA. Weathering COVID-19 storm: Successful control measures of five Asian countries. American Journal of Infection Control. 2020;48(7):851-2.

[38] Dargaville T, Spann K, Celina M. Opinion to address the personal protective equipment shortage in the global community during the COVID-19 outbreak. Polymer Degradation and Stability. 2020; 176:1091622.

[39] Inaba M, Naito H, Sakata T. COVID-19 pandemic and shortage of personal protective equipment in Tokyo clinics. Medicine \& Surgery. 2020;7:e527.

[40] World Health Organization, Rational use of personal protective equipment (PPE) for coronavirus disease (COVID-19). Interim guidance. 2020:1-7. Available from: https://www.who.int/publications/i/item/rational-use-ofpersonal-protective-equipment-for-coronavirus-disease(covid-19)-and-considerations-during-severe-shortages.

[41] Koh D. Occupational risks for COVID-19 infection. Occupational Medicine. 2020;70:3-5.

[42] Turkish Thoracic Society (TORAKS). Covid-19 infection is a work-related disease for healthcare workers. Available from: https://www.toraks.org.tr/userfiles/file/Rapor(2).pdf.

[43] Occupational Safety and Health Administration (OSHA). Guidance on preparing workplaces for COVID-19. 2020. Available from: https://www.osha.gov/Publications/OSHA 3990.pdf. 